\title{
Simulating mustard crop phenology and productivity with InfoCrop-Mustard model under temperature increase scenarios
}

\author{
K. K. GILL, BALJEET KAUR, S. S. SANDHU and PRABHJYOT KAUR \\ School of Climate Change \& Agrilcultural Meteorology \\ Punjab Agricultural University, Ludhiana - 141004 \\ *Corresponding author e-mail: kgill2002@gmail.com
}

\begin{abstract}
The InfoCrop-mustard model was calibrated and validated using field experiment conducted during 2010-11 to 213-14 at research farm of Punjab Agricultural University Ludhiana, Punjab, having three dates of sowing $\left(25^{\text {th }}\right.$ October, $5^{\text {th }}$ November and $15^{\text {th }}$ November) and three crop cultivars (PBR 91, Hyolla PAC 401 and GSL 1). The simulated crop phenology and seed yield agreed fairly well with field observations. The validated model was used to simulate the response of mustard to increase in temperatures on crop productivity. The seed yield decreased linearly as a result of increase in maximum and minimum temperatures. The study revealed that the InfoCrop-Mustard model can be used to predict crop phenological events and productivity under presumptive climate change scenarios in central Punjab.
\end{abstract}

Keywords: Crop modelling, InfoCrop-Mustard calibration and validation, climate change, Central Punjab.

Oilseed crops represent the second major group amongst agricultural crops and play an important role in agriculture and industrial economy of India. Rapeseedmustard forms an important group of oilseeds next only to soybean. It also is the second most important edible oilseed after groundnut sharing 27.8 per cent of oilseed economy in India.

Weather is the major variable impacting crop production in agricultural systems (Sharma, 2004). Mustard is very sensitive to climatic parameters and hence climatic changes could have significant effect on productivity. Arvind Kumar (2005) indicated that a part of the decline or stagnation in mustard yields leading to negative growth rate from 1997 was possibly due to unfavorable monsoon which created either drought or excess rainfall conditions and also temperature stress. Higher temperature during mustard crop establishment (mid October to early November) while cold spell, fog and intermittent rains during crop growth affect the crop adversely. Further, these conditions lead to occurrence and proliferation of aphids, white rust, downy mildew and stem rot diseases. Mall et al (2004) reported that crop production in winter season might become comparatively more vulnerable due to larger increase in temperature and higher uncertainties in rainfall. On the other hand, global warming impact could likely be offset to some extent by increased $\mathrm{CO}_{2}$ levels in atmosphere, although the magnitude of these effects are uncertain and this needs more debate and research (Long et al, 2005, 2006). Overall, the temperature increases are likely to be much higher in winter season when mustard is grown. In this season, precipitation is also likely to decrease. These changes in climate may affect the crop yields and the economic costs of agricultural production due to incidence of weeds, insect and plant diseases. Few studies from India (Saseendran $e t$ al, 2000; Aggarwal, 2008) also point out to decline in agricultural production with climate change. According to Boomiraj et al (2010) temperature rise would be most harmful for the crop in eastern region of India, followed by central India, where winter season temperature is comparatively higher than northern region. Easterling et al (2007) analyzed modeling results to show that in low-latitude regions, a temperature increase of $1-2^{\circ} \mathrm{C}$ is likely to have negative yield impacts for major cereals. There is a probability of 10 $40 \%$ loss in crop production in India with increase in temperature by 2080-2100 (Fischer et al., 2007; Parry et al., 2004; IPCC, 2007).

Only limited studies have been done to assess the impact of climate change on oilseed crops, especially in Punjab. Therefore, the objectives of this study were to calibrate and validate InfoCrop-Mustard model and to apply the model to evaluate the impact of changes in temperature and sunshine hours on productivity of mustard crop.

\section{MATERIALS AND METHODS}

InfoCrop-mustard model version 1.1 provides 
Table 1: Genetic coefficients used for different cultivars of mustard (PBR 91, GSL 1 and Hyolla PAC 401) to run InfoCropmustard model

\begin{tabular}{|c|c|c|c|c|}
\hline Genetic Coefficients & Units & PBR 91 & GSL 1 & Hyolla PAC 401 \\
\hline TTGERM & ${ }^{\circ} \mathrm{C}$ day $^{-1}$ & 58 & 55 & 55 \\
\hline TTVG & ${ }^{\circ} \mathrm{C}$ day $^{-1}$ & 733 & 730 & 750 \\
\hline TTGF & ${ }^{\circ} \mathrm{C}$ day $^{-1}$ & 953 & 950 & 940 \\
\hline TGMBD & ${ }^{\circ} \mathrm{C}$ & 5 & 5 & 5 \\
\hline TBASE & ${ }^{\circ} \mathrm{C}$ & 5 & 5 & 5 \\
\hline TGBD & ${ }^{\circ} \mathrm{C}$ & 5 & 5 & 5 \\
\hline TOPT & ${ }^{\circ} \mathrm{C}$ & 20 & 20 & 20 \\
\hline TMAX & ${ }^{\circ} \mathrm{C}$ & 40 & 40 & 40 \\
\hline$\overline{\text { RUE }}$ & gMJday $^{-1}$ & 2 & 1.9 & 1.8 \\
\hline$\overline{R G R L}$ & ${ }^{\circ} \mathrm{C}$ day $^{-1}$ & 0.008 & 0.008 & 0.008 \\
\hline$\overline{\text { SLA }}$ & $\mathrm{dm}^{2} \mathrm{mg}^{-1}$ & 0.001 & 0.001 & 0.001 \\
\hline Extinction Coefficient of & ha soil ha-1 & & & \\
\hline leaf at flowering & leaf fraction & 0.6 & 0.6 & 0.6 \\
\hline Slope of organ number $/ \mathrm{m}^{2}$ & storage organ & & & \\
\hline to dry matter & $\mathrm{kg}^{-1} \mathrm{day}^{-1}$ & 2800000 & 2800000 & 2800000 \\
\hline Potential storage organ weight & $\mathrm{mg}^{-1}$ grain & 8 & 8 & 8 \\
\hline Nitrogen content & fraction & 0.039 & 0.039 & 0.039 \\
\hline
\end{tabular}

integrated assessment of the effect of weather, variety, pests and soil and management practices on crop growth and yield as well as on soil nitrogen and organic carbon dynamics in aerobic as well anaerobic conditions and green house emissions. The model considers the key processes related to crop growth and its general structure is related to basic crop growth and yield is largely based on several earlier models. The input requirements of the model are: crop and variety, weather (season and location), weather data (temperature and sunshine hours), soil properties, dates of planting, seed rate and depth of planting, soil water and nitrogen at the time of start of the simulation.

The InfoCrop-Mustard model was calibrated by using crop data for three Brassica cultivars, viz., PBR 91, GSL 1 and Hyolla PAC 401 sown on three dates i.e., $25^{\text {th }}$ October, $5^{\text {th }}$ November and $15^{\text {th }}$ November over three crop seasons of 2010-11, 2011-12 and 2012-13 included in published reports of the School of Climate Change and Agricultural Meteorology, PAU Ludhiana. The data related to seed yield and occurrence of different phenological stages viz., sowing, emergence, flowering, pod formation, pod filling and physiological maturity were used for calibration and validation of model. The weather data on maximum and minimum temperature, vapour pressure, sunshine hours, rainfall and wind speed was collected from the meteorological observatory located at the nearby the field. The model was validated by using the data of field experiment conducted at the Research Farm in rabi season of 2013-14 using same varieties and dates of sowing. The irrigation and fertilizer dose were applied as per recommendations provided in package of practices by the Punjab Agricultural University. The model simulated flowering and physiological maturity and seed yield of mustard which were compared with actual field observations. After calibration and validation of the InfoCrop simulation model, it was used to predict crop response to presumptive temperature increase scenarios compared to normal temperatures throughout the crop growing season. The presumptive changes were assumed to be an increase in maximum and minimum daily temperature above the normal by 0.5 to $3.0^{\circ} \mathrm{C}$ in $0.5^{\circ} \mathrm{C}$ increments.

The values of genetic coefficients used for calibration of model are given in Table 1. are the thermal times $\left({ }^{\circ} \mathrm{Cd}^{-1}\right)$ required by crop to reach a particular growth stage, maximum temperature for development, optimum temperature for development, base temperature, relative growth rate of leaf area, specific leaf area, extinction coefficients, radiation use efficiency, slope of relationship between storage organ number and dry matter accumulated during the formation stage, potential weight of storage organs and nitrogen content of the storage organs. 


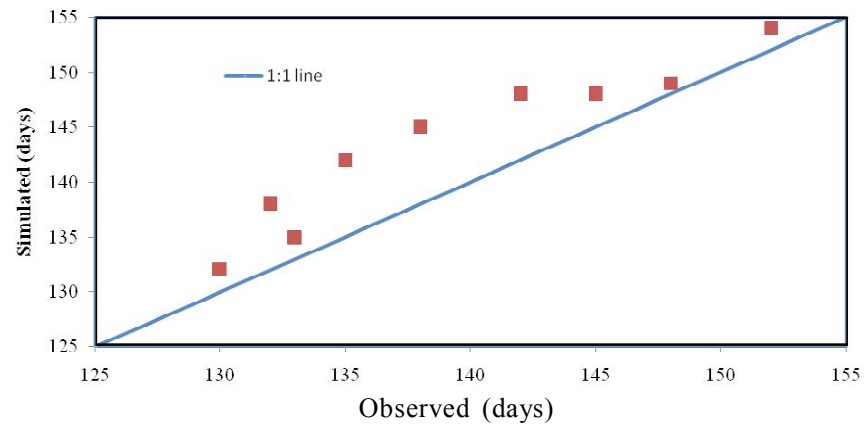

Fig. 1 : Comparison of simulated and observed days to phsiological maturity of mustard cultivars under different dates of sowing

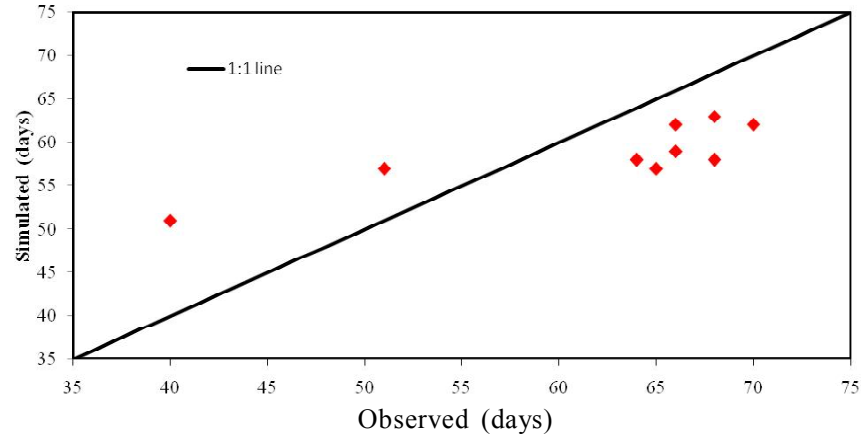

Fig. 2 : Comparison of simulated and observed days to flowering of mustard cultivars under different dates of sowing

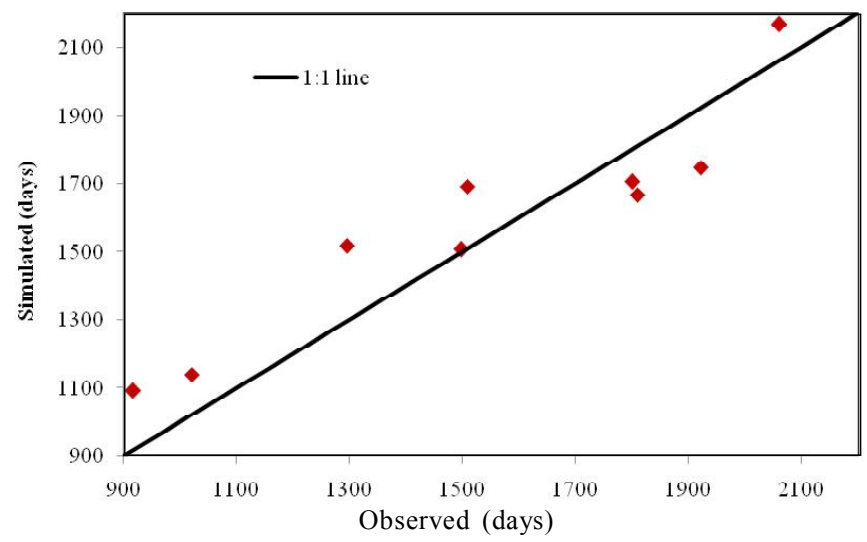

Fig. 3 : Comparison of simulated and observed seed yield of mustard cultivars under different dates of sowing

\section{RESULTS AND DISCUSSION}

\section{Calibration of model}

The InfoCrop-mustard model was calibrated for specific crop growth parameters for three Brassica cultivars, sown on three dates of sowing during the three crop growing seasons. First, the model simulated values of flowering stage, physiological maturity stage and seed yield which were tabulated and compared with field observed values to observe the difference between the two. Then values of each phenological and growth coefficient, which minimized the difference between observed and simulated values for all those parameters were selected in an iterative manner.

\section{Validation of model}

The calibrated model was validated using field experimental data collected during rabi season of 2013-14. The simulated flowering, physiological maturity dates and seed yields of mustard were compared with actual observations (Fig. 1, 2 and 3).

Crop phenology : Simulated days to flowering were compared with observed data for early, normal and late sown crop (Fig. 1 ). The model predicted the days to flowering between -10 to +11 days of the observed values. The observed days to flowering were in range of 40-70 days after sowing (DAS) and simulated days to flowering were 51-63 DAS. The model overestimated the days to flowering for PBR 91 and Hyolla PAC 401 under $1^{\text {st }}$ date of sowing $\left(25^{\text {th }}\right.$ October $)$ while it underestimated the days to flowering for rest of the treatments. Keeping in view that even the field observed phenological dates can differ or be biased based on personal judgement of the observers, these trends showed that the model was able to simulate flowering period reasonably well for all treatments.

The model satisfactorily simulated days to physiological maturity (Fig. 2). The physiological maturity dates simulated by the model correspond reasonably well with those actually observed in the field during 2013-14. The model overestimated physiological maturity for PBR91 from 1-6 days under three dates of sowings. In case of varieties GSL 1 and Hyolla PAC 401 the model overestimated the physiological maturity dates by 2-6 and 2-7 days, respectively. Simulated physiological maturity occurred between 132-154 DAS, whereas observed values were between 130-152 DAS for all the treatments. Simulated physiological maturity dates were either at par or were overestimated by the model up to 2-7 days compared to the field observed dates.

Seed yield : The comparison of observed and predicted seed yield revealed both over-estimation and under-estimation by the model (Fig. 3). The observed as well as simulated seed yield was maximum for cultivar PBR 91 on all dates of sowing and least for cultivar Hyolla PAC 401. The model also simulated higher yields for early date of sowing as observed in the field. The yield was slightly over estimated by the model for $25^{\text {th }}$ October sown for PBR 91 (2168.0 $\left.\mathrm{kg} \mathrm{ha}^{-1}\right)$ and was slightly under estimated for Hyolla PAC 401 and GSL 1. Overall, the simulated yields deviated by $-9.9 \%$ to $14.7 \%$ for PBR $91 ;-8.5$ 
Table 2: Statistical values for testing the difference between observed and simulated yield

\begin{tabular}{lrrrrr}
\hline Parameter & Observed & Simulated & ME (\%) & RMSE (\%) & $\mathrm{R}^{2}$ \\
\hline Days to flowering & 62.0 & 58.6 & 96.9 & 9.1 & 0.45 \\
Days to physiological maturity & 139.4 & 143.4 & 99.1 & 9.7 & 0.55 \\
Seed yield $\left(\mathrm{kg} \mathrm{ha}^{-1}\right)$ & 1537.2 & 1583.0 & 79.5 & 1.7 & 0.84 \\
\hline
\end{tabular}

RMSE - Root Mean Square Error

Table 3: Rate of change in seed yield of mustard crop with change in temperature from normal

\begin{tabular}{lll}
\hline Parameters & $\begin{array}{l}\text { Change in } \\
\text { temperature }\left({ }^{\circ} \mathrm{C}\right)\end{array}$ & $\begin{array}{l}\text { Yield } \\
\text { deviation }(\%)\end{array}$ \\
\hline Maximum & +0.5 & 3.3 \\
& +1.0 & -1.6 \\
& +1.5 & -3.9 \\
& +2.0 & -6.6 \\
& +2.5 & -10.6 \\
Minimum & +3.0 & -28.9 \\
& +0.5 & -5.8 \\
& +1.0 & -7.0 \\
& +1.5 & -10.0 \\
& +2.0 & -14.3 \\
& +2.5 & -24.8 \\
& +3.0 & -32.8 \\
\hline
\end{tabular}

$\%$ to $10.8 \%$ for GSL 1 ; and $-5.5 \%$ to $16.0 \%$ for Hyolla PAC 401 under all the three dates of sowing . The validation results obtained with the model for the 2013-14 crop season demonstrated satisfactory predictions of phenological events, growth and yield of Mustard crop.

From the statistical parameters (Table 2), it is evident that InfoCrop-mustard model can be used to predict phenology and seed yield effectively after calibration of the model with cultivar specific coefficients. The model efficiency was $96.9 \%$ for days to flowering, $99.1 \%$ for days to physiological maturity and $79.5 \%$ for seed yield. The values of root mean square error were $9.1 \%, 9.7 \%$ and $1.7 \%$ for days to flowering, physiological maturity and seed yield, respectively. The $\mathrm{R}^{2}$ values for flowering, physiological maturity and seed yield were $0.45,0.55$ and 0.84 , respectively.

Results showed that InfoCrop-mustard model was in general able to simulate the temporal change of flowering and physiological maturity satisfactorily in all three treatments and can be satisfactorily used for the prediction
ME - Model Efficiency

of mustard growth and yield in central irrigated plains of Punjab.

\section{Effect of increase in temperatures on crop productivity}

In the climate change study, the maximum and minimum temperatures were increased in increments of $0.5^{\circ} \mathrm{C}$ up to $3^{\circ} \mathrm{C}$ above the normals, either singly or together, for the entire crop growth period and the crop was assumed to be free from water and nutrient stress and pest infestation. The crop yield simulated by the model under modified temperature regimes deviated from the normal conditions by 3.3 to -28.9 per cent when maximum temperature was increased from 0.5 to $3.0^{\circ} \mathrm{C}$ (Table 3 ). A slight positive deviation was obtained when maximum temperature was increased by $0.5^{\circ} \mathrm{C}$. The maximum decrease in yield $(-28.9 \%)$ was found when maximum temperature increased by $3.0^{\circ} \mathrm{C}$.

The deviation in crop yield was found to be in the range of -5.8 to -32.8 per cent when minimum temperatures were increased from $0.5^{\circ} \mathrm{C}$ to $3.0^{\circ} \mathrm{C}$. The negative deviations were much greater in magnitude for minimum temperature increases as compared to those of maximum temperatures.

\section{CONCLUSIONS}

Results from this simulation study revealed that InfoCrop-Mustard model can successfully simulate growth and yield of mustard crop. Similarly compared to late sowing, the early sowing resulted in highest yield for all three cultivars. Simulated yield of mustard was found to be sensitive to increases in temperature. The seed yield decreased drastically with increase in minimum and maximum temperatures. In order to get potential yields the adaptation strategies like early sowing and growing longer duration variety would be beneficial.

\section{REFERENCES}

Aggarwal P. K. (2008). Impact of climate change on Indian agriculture: impacts, adaptation and mitigation. Ind.J.Agri. Sci. 78:911-19.

Kumar, Arvind. (2005). Rapeseed-mustard in India: current status and future prospects. Proceedings of Winter 
School on Advances in Rapeseed-Mustard Research Technology for Sustainable Production of Oilseeds, National Centre on Rapeseed-Mustard, Sewar, Bharatpur, 15 December to 04 January, 2005. pp. 27888 .

Boomiraj, K.,Chakrabarti, B., Aggarwal, P. K., Choudhary, R.andChander, S.(2010). Assessing the vulnerability of Indian mustard to climate change. Agri.Ecosys. Enviro. 138: 265-73.

Easterling, W.E., Aggarwal, P.K., Batima, P., Brander, K. M., Erda, L., Howden, S. M., Kirilenko, A., Morton, J., Soussana, J.F., Schmidhuber, J. andTubiello, F. N.(2007). Food, fibre and forest products climate change. pp 273-313. Proceedings of report on Impacts, Adaptation and Vulnerability. Contribution of Working Group II to the Four the Assessment Report of the InterGovernmental Panel on Climate Change. Parry ML, Canziani OF, Palutikof JP, van der Linden PJ and Hnason CE(Eds).Cambridge University Press, Cambridge UK.

Fischer, G., Tubiello, F.N., Velthuizen, H.V., Wiberg, D.A.(2007). Climate change impacts on irrigation water requirements: effects of mitigation, 1990-2080. Technology Forecasting Social Change 74, 1083-1107, doi:10.1016/j.techfore.2006.05.021.

Kumar, S.N., Bai, K.V., Rajagopal, V. andAggarwal, P.K. (2008). Simulating coconut growth, development and yield with the InfoCrop-coconut model. Tree Phys., 28: 1049-
58.

Long, S.P.,Ainsworth, E.A., Leakey,A.D.B., Morgan, P. B.(2005) Global food insecurity. Treatment of major food crops with elevated $\mathrm{CO}_{2}$ or ozone under large scale fully open air conditions suggests recent models may have overestimated future yields. Phil. Trans. R. Soc. B, 360: 2011-20.

Long, S.P., Ainsworth, E. A., Leakey, A., Nosberger, J. and Ort, T.R. (2006). Food for thought: lower than expected crop yield simulation with raised $\mathrm{CO}_{2}$ concentrations. Science, 312: 1918-21.

Mall, R.K., Lal, M., Bhatia, V.S., Rathore, L.S. and Singh, R. (2004).Mitigating climate change impact on soybean productivity in India: a simulation study. Agril. Forest Meteorol, 121:113-25.

ParryML, Rosenzweig C, Iglesias, Livermore AM and Fischer G. (2004). Effects of climate change on global food production under SRES emission and socioeconomic scenarios. Global Environ. Change, 14: 53-67.

Saseendran, S.A., Singh, K.K., Rathore, L. S., Singh, S. V. and Sinha, S. K.(2000). Effects of climate change on rice production in the tropical humid climate of Kerala, India. Climatic Change, 44: 495-514.

Sharma, K. D.(2004). Role of weather variables in plant physiological process. Weather based Agro Advisory: value addition. Pp 56-60. 